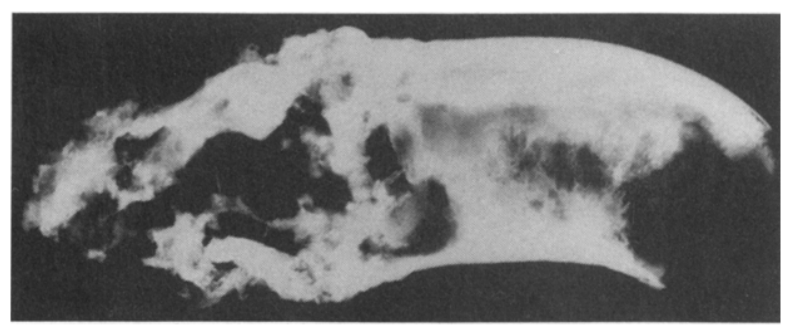

Fig 1. Radiography of the calcified explanted conduit.

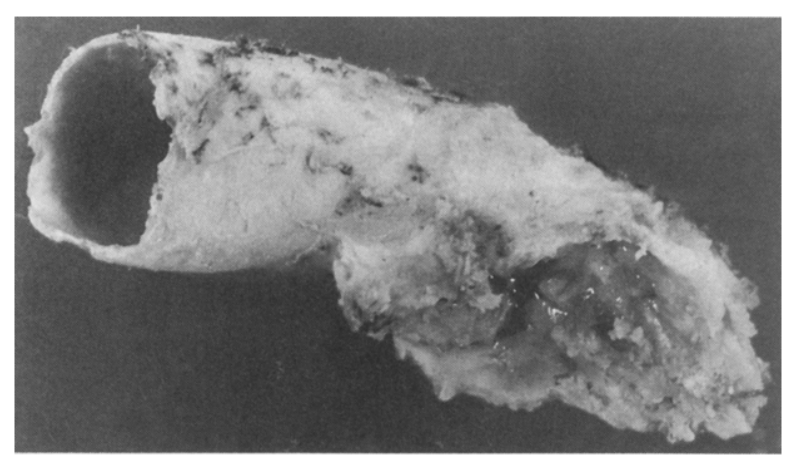

Fig 2. Macroscopic appearance of the calcified explanted conduit.

as histologic study, confirmed the extensive calcification of the aortic homograft, in situ for 21 years 8 months.

Antonio Corno, MD

Pediatric Cardiac Surgery

University Lausanne-Clinique de Genolier

Genolier CH-1272, Switzerland

12/8/92305

\section{Delayed iatrogenic aortic dissection from coronary bypass}

\section{To the Editor:}

I enjoyed the recent article, "Delayed Iatrogenic Aortic Dissection From Coronary Bypass Managed With Extraanatomic Bypass," by Pappas and associates (J Thorac Cardiovasc Surg 1998;115:947-9).
Fig 1, showing the computed tomographic scan of the chest, appeared to demonstrate a significant peri-aortic collection of blood, in addition to the dissection. I wondered whether the authors were concerned about a leak in the descending thoracic aorta and how they would have managed this clinical situation.

Inasmuch as the authors decided on a nonoperative approach, another option would have been catheter fenestration and stenting of the involved vessels. After repair of type I dissection, I have used catheter fenestration and postfenestration stents to alleviate leg ischemia. This option avoids an axillary bifemoral bypass or femoral-femoral bypass.

Frank A. Baciewicz, Jr, MD

Department of Cardiothoracic Surgery Wayne State University-Harper Hospital 3990 John R, Ste 2120

Detroit, MI 48201

$12 / 8 / 92938$

Reply to the Editor:

The computed tomographic scan of the chest, shown in Fig 1, was performed after the operation. We did not have a preoperative scan. The patient was in hemodynamically stable condition and was having no symptoms of progressive dissection. Thus nothing further was done.

We agree that catheter fenestration and stenting would have been another option to alleviate leg ischemia. However, at our institution we were more comfortable with surgical extraanatomic bypasses.

George L. Hines, MD Chief, Division of Vascular Surgery Winthrop-University Hospital 259 First $S t$

Mineola, NY 11501 12/8/92937

Fiftieth anniversary of the insertion of an artificial heart valve

To the Editor:

In an article titled "Una Valvula Aortica Artificial" by Dr Isidro Perianes and me, we presented at the International 